\title{
Scholarly Productivity in Non-Ph.D. Departments
}

Todd A. Collins, Western Carolina University

Christopher A. Cooper, Western Carolina University

H. Gibbs Knotts, Western Carolina University

ABSTRACt Political scientists hail from large, research-intensive universities like the Ohio State University, regional comprehensive schools like Western Kentucky University, and small teaching-intensive institutions like Mars Hill College. Despite this diversity, most studies of the political science discipline overlook the contributions of individuals from non-Ph.D. departments. To address this oversight, we compare the publishing rates of scholars with four types of affiliations: non-Ph.D. departments, Ph.D. departments, nonU.S. departments, and nonacademic institutions. We focus particularly on whether faculty from non-Ph.D. departments publish in different types of journals than faculty from other departments, and whether the institutional affiliations of editorial board members corresponds to the institutional affiliations of published authors. We find that people from non-Ph.D. departments represent $16 \%$ of the authors in our sample of political science journals, and their contributions are particularly noteworthy in certain types of journals. We also demonstrate that the institutions represented on editorial boards generally do not reflect the institutional affiliations of the authors who publish in these journals.

Todd A. Collins is an assistant professor of political science and public affairs at Western Carolina University. His research on judicial behavior and public law has appeared in outlets such as Political Research Quarterly, Law and Policy, White House Studies, and the University of Maryland Law Review. He can be reached at tcollins@email.wcu.edu.

Christopher A. Cooper is an associate professor of political science and public affairs and director of the Public Policy Institute at Western Carolina University. His research on state politics, political communication, political behavior, and Southern politics has been published in a variety of outlets, including Public Administration Review, Political Research Quarterly, American Politics Research, Social Forces, Social Science Quarterly, and State Politics and Policy Quarterly. He can be reached at ccooper@email.wcu.edu.

H. Gibbs Knotts is an associate professor and department head of political science and public affairs at Western Carolina University. His research on political behavior, Southern politics, and public administration has appeared in outlets including the Journal of Politics, Public Administration Review, Social Science Quarterly, Social Forces, PS: Political Science and Politics, and State Politics and Policy Quarterly. He is co-editor of the New Politics of North Carolina (2008, University of North Carolina Press). He can be reached at gknotts@email.wcu.edu.

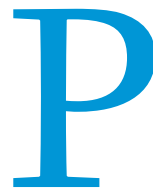

olitical scientists have a fondness for rankings. We rank our journals (Garand and Giles 2003; Giles and Garand 2007), our book presses (Goodson, Dillman, and Hira 1999), our departments (Ballard and Mitchell 1998; Garand and Graddy 1999; Hix 2004; Masuoka, Grofman, and Feld 2007b; Miller, Tien, and Peebler 1996), our graduate programs (McCormick and Rice 2001), and each other (Klingemann, Grofman, and Campagna 1989; Masuoka, Grofman, and Feld 2007a). These rankings have elicited considerable discussion-particularly from those people who believe that their department, favorite journal, or university classification has received unfair treatment (e.g., Thatcher and Thatcher 2007; Crowe and McWilliams 2008; Frederking 2008). Of course, these debates are not unique to political science. Economists (Kalaitzidakis, Mamuneas, and Stengos 2001), psychologists (Anseel et al. 2004; Boor 1982), and sociologists (Allen 1990) also engage in byzantine debates over rankings. 
Although some people might dismiss these debates as pointless navel-gazing, tenure decisions, hiring decisions, and career choices are often made based on disciplinary rankings. It is not uncommon for academics to define career success by departmental and journal rankings. Publication in one of the "big three" journals (American Political Science Review, American Journal of Political Science, and Journal of Politics) can serve as a defining moment in the career of a political scientist, and even the least vain among us would prefer to have our work published in more highly ranked journals than those outlets with less prestige.

Absent from many of these discussions, however, are the scholarly contributions of people from departments that do not offer a $\mathrm{Ph}$.D. For example, many studies of political science departmental rankings build upon the National Research Council's study of departments with Ph.D. programs (e.g., Garand and Graddy 1999; Ballard and Mitchell 1998), thus excluding scholars from departments that only grant bachelors' or masters' degrees. Recent studies such as the "Political Science 40o" (Masuoka, Grofman, and Feld 2007a) do not consider the productivity of scholars from nonPh.D. departments. In addition, when journals are ranked and scored by reputation, academics from non-Ph.D. departments are often not invited to respond to the survey (Giles and Wright 1975; Giles, Mizell, and Paterson 1989; for an alternative approach, see Garand and Giles 2003).

Ignoring the work of scholars from non-Ph.D. departments leaves out nearly half of the political scientists in the country. Approximately $44 \%$ of the American Political Science Association's (APSA 2008) nonstudent membership works at a non-Ph.D. institution. Moreover, non-Ph.D.-granting institutions compose well over half of the members of the Interuniversity Consortium for Political and Social Research (ICPSR 2008). Scholars have noted the research potential of these non-Ph.D.-granting departments, including one recent article published in the Chronicle of Higher Education that argued that, "for junior faculty members, the best place to focus on research may not be at a research university" (Ghodsee 2008, C1). Many scholars have even called for more consideration of non-Ph.D. departments as first-choice career opportunities for academics (Crowe and McWilliams 2008; Frederking 2008; Ghodsee 2008; Henderson 2007).

To gain a better understanding of the scholarly productivity of non-Ph.D. departments, we focus on three primary research questions. First, what are the publishing rates of scholars from nonPh.D. departments? Second, do faculty from non-Ph.D. departments publish in different types of journals than do faculty from Ph.D.granting departments? Third, do the affiliations of a journal's editorial board members correspond to the institutional affiliations of published authors in that journal?

\section{DATA AND METHODS}

Many studies analyzing journal authorship focus on the top three journals in the discipline. Because one of the primary research questions of our study is whether an author's institutional affiliation varies by journal, however, we expanded the universe of journals evaluated and coded every article longer than two pages in 26 top political science journals from 2000 to 2007.

To create our sample of journals, we began with the journals with the 20 highest impact ratings, as reported by Garand and Giles (2003). We then excluded three journals that were outside of the political science field (American Sociological Review, American
Economic Review, American Journal of Sociology). Although many political scientists publish in journals outside of their discipline, we wanted this initial study to focus on publication rates within the discipline's journals.

Following work about publishing patterns in sociology (Eckberg and Marx 2004; Marx and Eckberg 2005), we also added nine of the official journals of the APSA's organized sections. We excluded New Political Science and Party Politics, official subfield journals, from this list because of access problems from our university library. In addition, since we began data collection, Politics and Religion and the Journal of Information Technology and Politics were added as new section journals. These journals were not included in our dataset. Despite some notable holes, this list should provide an understanding of publishing across subfields.

We should also note that the author, rather than the article, is the unit of analysis. We made this coding decision because we did not want to unnecessarily discount coauthored contributions. Coauthorship is increasingly common and accepted within political science (Chandra et al. 2006; Fisher et al. 1998; Sigelman 2006). As King notes, "In most of the social sciences, credit is not divided among the coauthors: each coauthor gets almost full credit for the entire paper" $(2006,121)$. Coauthored articles are even cited more than their single-authored counterparts (Montpetit, Blais, and Foucault 2008).

We classified each author into one of four affiliations: authors affiliated with departments in the United States that do not offer a Ph.D. (hereafter referred to as non-Ph.D. departments), authors affiliated with departments in the United States that do offer a Ph.D. (Ph.D. departments), authors affiliated with departments located outside of the United States (non-U.S. departments), and authors affiliated with an organization located outside of the higher education system (nonacademic institutions). The process of classifying authors was fairly straightforward for non-U.S. departments and nonacademic institutions. Likewise, in cases in which a department offers a Ph.D. in political science, we simply coded the author as being located in a Ph.D. department. However, some departments have Ph.D. programs in areas related to political science, such as public administration and policy. Although such a program is not a Ph.D. in political science, it is offered by the department, and presumably, department members receive many of the benefits of a Ph.D. program. As a result, we coded authors from these types of departments and similarly situated programs as Ph.D. departments. Another issue arose concerning departments without a Ph.D. program located in a state flagship offering Ph.D.s in other fields. Although the department is embedded in a larger, research-oriented university, no Ph.D.s are granted within the department, and we therefore coded authors from these departments as non-Ph.D. departments.

Another challenge related to coding academics who are not political scientists. Although sociologists, economists, and public administration scholars publish in political science journals, we coded all authors as if they were political scientists. This issue is not a large problem, because when non-political scientists are represented, they are much more likely to work at universities in which virtually every department offers a Ph.D. or else no departments offer a Ph.D. The decision to collapse all categories into one was also necessary because many journals do not include department affiliation, making it very difficult to track down the specific affiliation of each author. 
Following the procedures outlined here, we compiled a dataset with 10,804 cases from 26 journals over a seven-year period. Table 1 shows all of the journals in our sample, the abbreviation for each journal, the rationale for inclusion, the number of cases coded, and the number of articles included. It is important to note that three of our journals (the Journal of Political Science Education, Politics and Gender, and State Politics and Policy Quarterly) were founded after 2000, and we therefore coded them beginning with their first issue.

As a further clue to the visibility of scholars from non-Ph.D. departments, we coded editorial boards from the 26 journals in our study. Rather than coding all years, we coded editorial boards from 2008, because we expect that editorial boards lag behind publication patterns. If editorial boards at least partially make up the pool of frequent writers for journals, we would expect to see publication patterns from 2000 to 2007 reflected in the editorial board memberships from 2008.

\section{PUBLICATION PATTERNS IN POLITICAL SCIENCE JOURNALS}

How much of the work in political science journals comes from scholars in departments without a Ph.D. program? Approxi- mately $16 \%$ of all the authors published in these 26 journals were affiliated with non-Ph.D.-granting departments, while faculty at Ph.D.-granting departments represented $66 \%$ of all the authors in the dataset. Moreover, approximately $13 \%$ of authors represented non-U.S. departments, and slightly fewer than $5 \%$ of the authors were affiliated with nonacademic institutions.

A primary goal of this study was to determine how authorship varies by journal type. The results, presented in figure 1, suggest that authorship patterns vary widely across journals. While political scientists from non-Ph.D. departments contributed to each journal in this study, these scholars appear to make their strongest impact in the discipline's teaching journal. Over $66 \%$ of the authors in the Journal of Political Science Education are affiliated with non-Ph.D. departments-a sign that academics from these departments may be particularly attuned to Boyer's (1990) call for more work on the scholarship of teaching and learning (see also Henderson and Buchanan 2007).

U.S. scholars not affiliated with Ph.D. departments also made substantial contributions to several other journals, representing at least one-quarter of authors in PS: Political Science and Politics (32\%), Publius (31\%), Politics and Gender (26\%), Policy Studies Journal (26\%), and Urban Affairs Review (25\%). Scholars from non-Ph.D. departments also represented at least one-fifth of authors in State Politics and Policy Quarterly (25\%), Political Science Quarterly (24\%), and Political Research Quarterly (23\%). Political scientists from non-Ph.D. departments appeared less frequently in journals published outside the United States or journals with a more international focus, including Political Analysis (3\%), British Journal of Political Science (4\%), World Politics (6\%), Journal of Conflict Resolution (6\%), and International Organization (6\%).

While the focus of our project was to assess publication rates by U.S. political scientists, our data also include contributions from nonacademics and faculty from educational institutions outside of the United States, as displayed in figure 2. Authors from nonacademic institutions represent less than $10 \%$ of authors in each of the journals included in our study, except Public Opinion Quarterly. The importance of public opinion research outside of academia likely explains the large number of contributions from nonacademics in this journal. In fact, 5 of the 32 
Figure 1

Publication Patterns of Authors from Ph.D. and Non-Ph.D. Departments

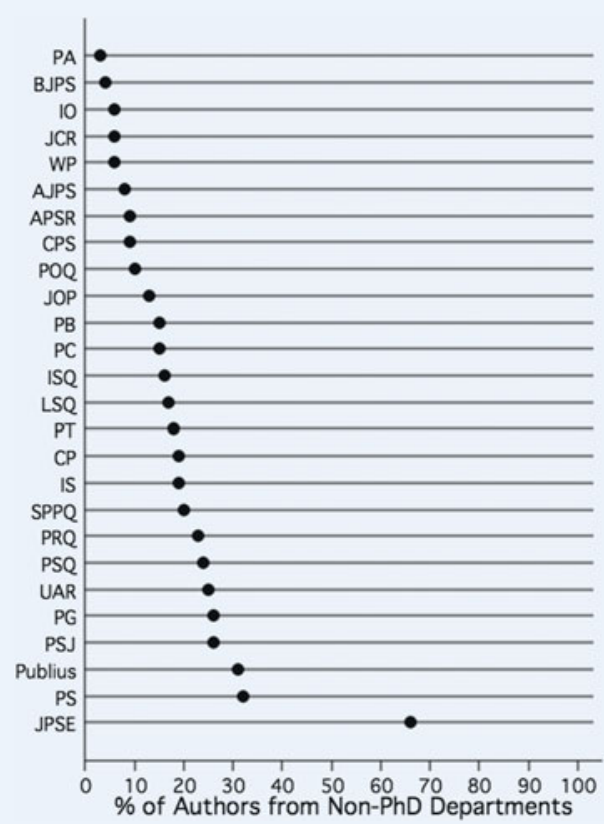

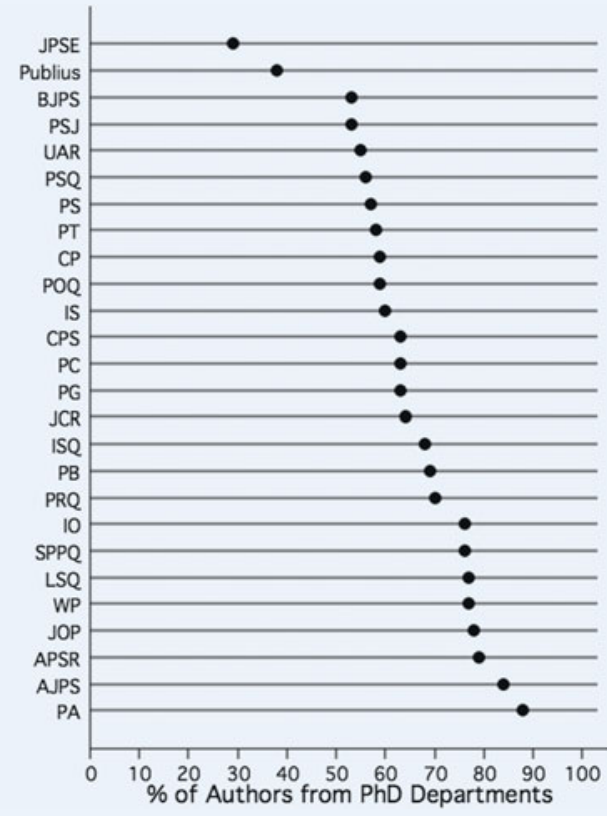

Figure 2

\section{Publication Patterns of Nonacademics and Authors from Non-U.S. Departments}

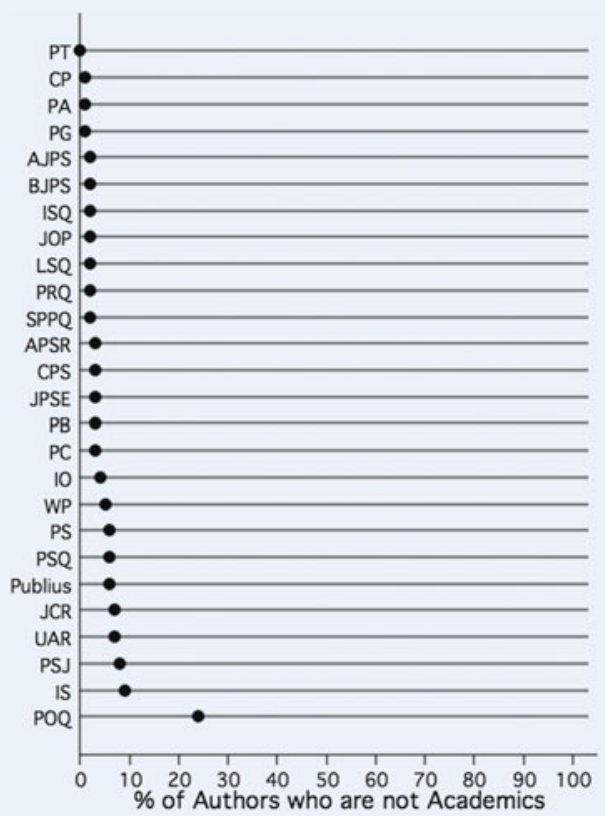

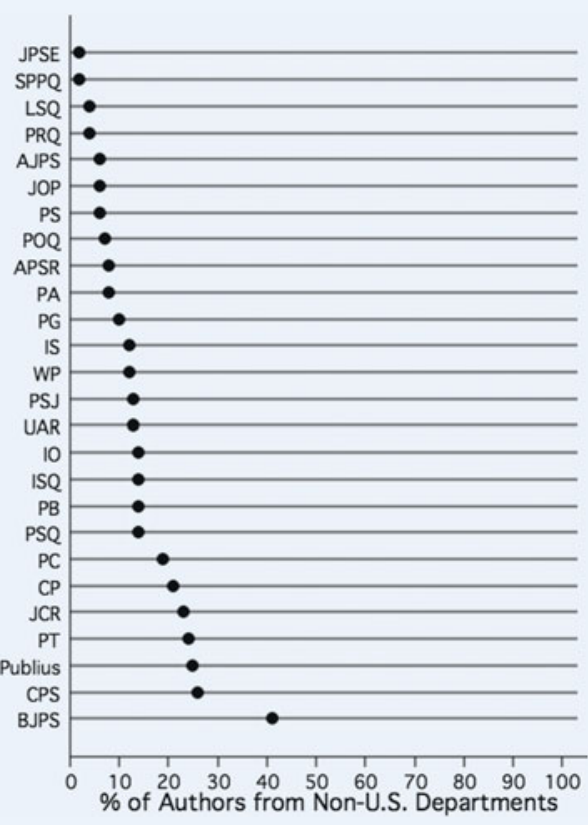

politics journals (see figure 2). The high percentage of authors from non-U.S. universities in Publius was somewhat surprising, although the journal does focus on federalism around the world. The Journal of Political Science Education and State Politics and Policy Quarterly have the lowest percentages of authors from non-U.S departments.

To better understand authorship affiliation and journal impact, figure 3 displays the relationship between the percentage of authors affiliated with non-Ph.D. departments and the Garand and Giles (2003) impact rankings. Some of the journals (e.g., State Politics and Policy Quarterly, the Journal of Political Science Education, and Politics and Gender) were not rated by Garand and Giles (2003) and thus are not included in figure 3 . The general trend, as displayed by the fitted values line, is that authorship by faculty from non-Ph.D. departments declines as the journal's impact ranking increases.

The journals above the line of best fit have a higher than expected proportion of authors from non-Ph.D. departments. For example, Publius, Political Science Quarterly, and Political Research Quarterly are well above the line, indicating that authors from non-Ph.D. departments publish at higher rates than expected in these journals, given the publications' impact rankings. Journals appearing below the line have a lower proportion of nonPh.D. authorship than expected from the impact rating. In the Journal of Conflict Resolution, British Journal of Political Science, and International Organizations, authorship by faculty from non-Ph.D. departments was less than expected, given these journals' impact rankings. As for the top three political science journals, scholars from non-Ph.D. departments represented just over $9 \%$ of the authors in the American Political Science Review, $8 \%$ of the authors in the American Journal of Political Science, and over $13 \%$ of the authors in the Journal of Politics. 


\section{Figure 3}

\section{Relationship between Impact Rating and Percentage of Authors from Non-Ph.D. Departments}

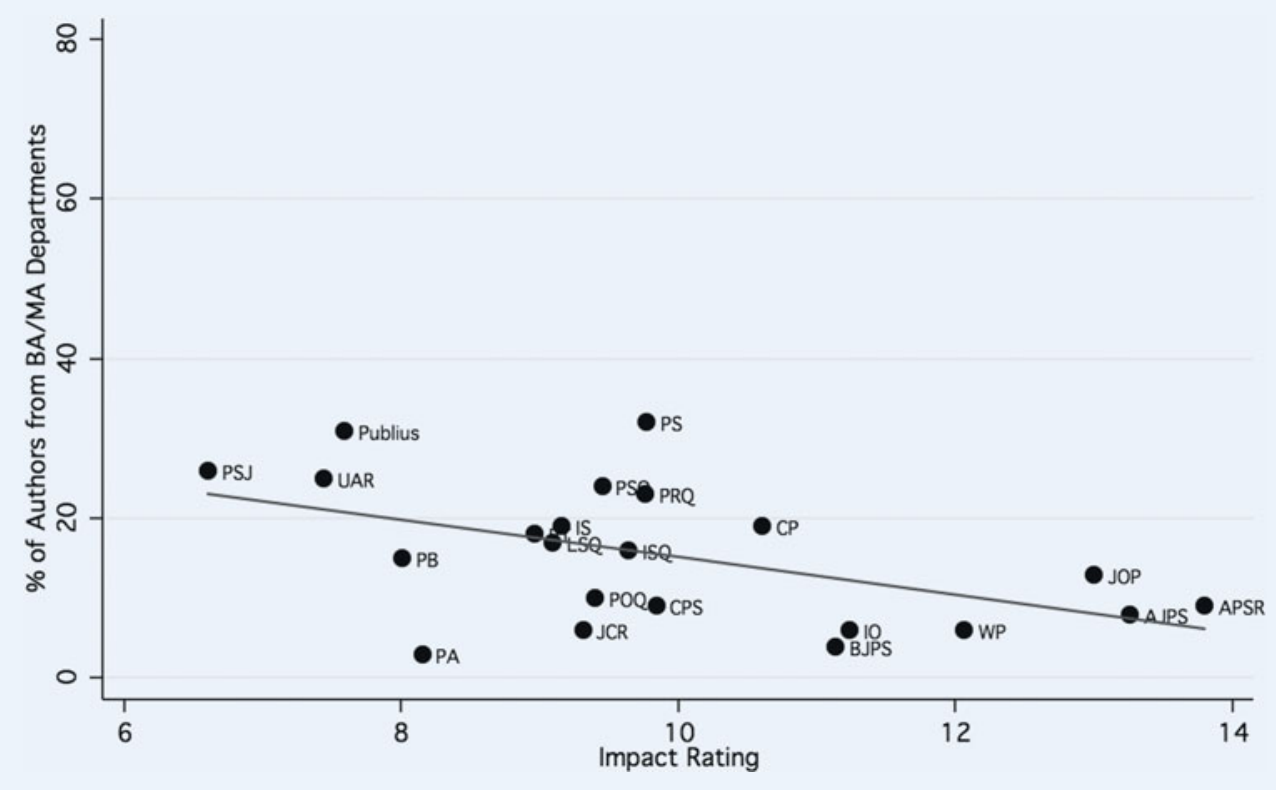

Figure 4

Editorial Board Membership, by Journal

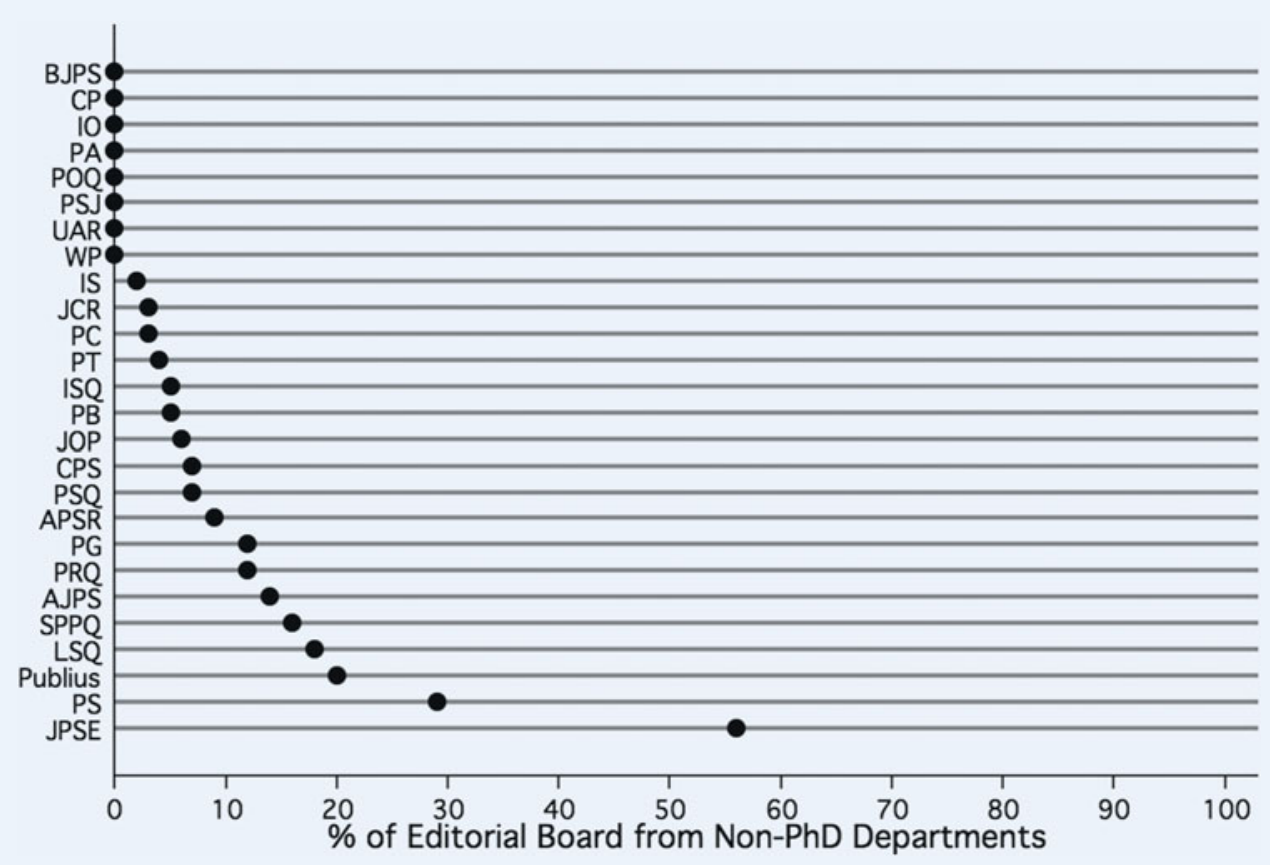

As figure 4 shows, political scientists from non-Ph.D. departments fill a significant number of positions on the board of the Journal of Political Science Education and, to a lesser extent, the boards of journals such as PS: Political Science and Politics (29\%), Publius (20\%), Legislative Studies Quarterly $(18 \%)$, and State and Politics and Policy Quarterly (12\%). However, many journals show much lower percentages of editorial board members from non-Ph.D. departments. For example, eight of the journals in this study (British Journal of Political Science, Comparative Politics, International Organizations, Policy Studies Journal, Political Analysis, Public Opinion Quarterly, Urban Affairs Review, and World Politics) lack a single editorial board member from a nonPh.D. institution.

Overall, scholars from nonPh.D. departments fill $9 \%$ of the 2008 editorial board seats in the 26 journals included in this study. This number is much lower than the $16 \%$ of authors from non-Ph.D. departments who publish in political science journals. Further, 23 of the 26 journals included in this study have a lower percentage of editorial board members from nonPh.D. departments than the percentage of published authors from non-PhD departments.

\section{CONCLUSIONS}

The contributions of scholars from non-Ph.D. departments have been largely ignored by studies of the discipline. Our results suggest that approximately $16 \%$ of authors in the 26 journals in our sample are from non-Ph.D. departments. For the first time, we also show empirical evidence that publication

Publication patterns are not the only way to examine the contributions of political scientists from non-Ph.D. departments. Editorial boards represent an important but rarely studied collection of productive scholars, and their members are often drawn from the pool of a journal's frequent contributors. We expect patterns of representation on editorial boards to be similar to patterns of representation in the pages of the journal. patterns differ widely by journal type, confirming a long-held presumption in the discipline. The three most prestigious journals are primarily the purview of scholars from Ph.D.-granting departments. Journals that focus on the scholarship of teaching and learning include many more contributions from scholars from non-Ph.D. departments. Subfield journals have much more variation. For example, few scholars from non-Ph.D. departments 
publish on political methodology, while subfields such as federalism, urban politics, and policy studies are more dominated by scholars from non-Ph.D. departments.

Similar to publication patterns, the institutional affiliations of editorial board membership also vary by journal. A few journals include no editorial board members from non-Ph.D. departments, despite publishing a considerable number of articles by authors from these schools. While almost $16 \%$ of authors come from non-Ph.D. departments, less than $9 \%$ of editorial board members hail from these departments.

Our findings also suggest a number of interesting directions for future research about the discipline. Most important, political science rankings should include scholars from all types of departments. Additional studies of the scholarly contributions of nonU.S. academics and people outside of academia should also be conducted. Future work can determine whether scholarly productivity is influenced by teaching load, research support, endowment, department size, and start-up packages. These results would be of considerable interest to department heads, deans, and other university administrators who wish to effectively incentivize and reward research activities.

\section{NOTE}

We would like to thank Brian Pollins for many helpful comments on an earlier version of this paper.

\section{REF E R E N C E S}

Allen, Michael Patrick. 1990. "The Quality of Journals in Sociology Reconsidered: Objective Measures of Journal Influence." Footnotes 18: 4-5.

American Political Science Association. 2008. APSA Membership and Governance Data Tables. http://www.apsanet.org/imgtest/IA1.pdf.

Anseel, Frederik, Wouter Duyck, Wouter Debane, and Marc Brysbaert. 2004. "Journal Impact Factors and Self-Citations: Implications for Psychology Journals." American Psychologist 19: 49-51.

Ballard, Michael J., and Neil J. Mitchell. 1998. "The Good, the Better, and the Best in Political Science." PS: Political Science and Politics 31: 826-28.

Boor, M. 1982. "The Citation Impact Factor: Another Dubious Index of Journal Quality." American Psychologist 37: 975-77.

Boyer, Ernest. 199o. Scholarship Reconsidered: Priorities of the Professoriate. New York: Carnegie Foundation for the Advancement of Teaching.

Chandra, Kanchan, Jennifer Gandhi, Gary King, Arthur Lupia, and Edwards Mansfield. 2006. Report of the APSA Working Group on Collaboration. American Political Science Association. http://www.apsanet.org/imgtest/ CollaborationReporto8-09-06.pdf.

Crowe, Justin, and Susan McWilliams. 2008. "Response to 'Ranking Programs in Political Science.”” PS: Political Science and Politics 41: 1.

Eckberg, Douglas, and Jonathan Marx. 2004. "The Mouse That Roared? Article Publishing in Undergraduate Sociology Program." American Sociologist 35: 58-78.
Fisher, Bonnie S., Craig T. Cobane, Thomas M. Vander Ven, and Francis T. Cullen. 1998. "How Many Authors Does it Take to Publish an Article? Trends and Patterns in Political Science." PS: Political Science and Politics 31: 847-56.

Frederking, Brian. 2008. "Response to Social Networks in Political Science." PS: Political Science and Politics 41: 2.

Garand, James C., and Michael W. Giles. 2003. "Journals in the Discipline: A Report on a Survey of American Political Scientists." PS: Political Science and Politics 36: 293-308.

Garand, James C., and Kristy L. Graddy. 1999. "Ranking Political Science Departments: Do Publications Matter?" PS: Political Science and Politics 32: 113-16.

Ghodsee, Kristen. 2008. "A Research Career at a Liberal Arts College." Chronicle of Higher Education, April 25.

Giles, Michael W., and James C. Garand. 2007. "Ranking Political Science Journals: Reputational and Citational Approaches." PS: Political Science and Politics 40: 741-51.

Giles, Michael W., Francie Mizell, and David Paterson. 1989. "Political Scientists' Journal Evaluation Revisited." PS: Political Science and Politics 22: 613-17.

Giles, Michael W., and Gerald C. Wright. 1975. "American Political Scientists' Evaluations of Sixty-Three Journals." PS: Political Science and Politics 8: 254-56.

Goodson, Larry P., Bradford Dillman, and Anil Hira. 1999. "Ranking the Presses: Political Scientists' Evaluations of Publisher Quality." PS: Political Science and Politics 32: 257-62.

Henderson, Bruce. 2007. Teaching at the People's University: An Introduction to the State Comprehensive University. Bolton, MA: Anker.

Henderson, Bruce B., and Heidi E. Buchanan. 2007. "The Scholarship of Teaching and Learning: A Special Niche for Faculty at Comprehensive Universities?” Research in Higher Education 48: 523-43.

Hix, Simon. 2004. "A Global Ranking of Political Science Departments." Political Studies Review 2: 292-313.

Interuniversity Consortium for Political and Social Research. 2008. "ICPSR Member Organizations." http://www.icpsr.umich.edu/membership/ors.html.

Kalaitzidakis, Pantelis, Theofanis P. Mamuneas, and Thanasis Stengos. 2001. "Rankings of Academic Journals and Institutions in Economics." http://www. le.ac.uk/economics/research/rankings/econ-rankings.html.

King, Gary. 2006. "Publication, Publication." PS: Political Science and Politics 39: $119-25$.

Klingemann, Hans-Dieter, Bernard Grofman, and Janet Campagna. 1989. "The Political Science 40o: Citations by Ph.D. Cohort and by Ph.D.-Granting Institutions." PS: Political Science and Politics 22: 258-70.

Marx, Johnathan, and Douglas Eckberg. 2005. "Teaching Scholarship during the 1990s: A Study of Authorship in Teaching Sociology." Teaching Sociology 33: $252-62$.

Masuoka, Natalie, Bernard Grofman, and Scott Feld. 2007a. "The Political Science 400: A 20-Year Update." PS: Political Science and Politics 40: 133-45.

_ 2007b. "Ranking Departments: A Comparison of Alternative Approaches." PS: Political Science and Politics 40: 531-37.

McCormick, James M., and Tom W. Rice. 2001. "Graduate Teaching and Research Productivity in the 1990s: A Look at Who Publishes." PS: Political Science and Politics 34: 675-80.

Miller, Arthur H., Charles Tien, and Andrew A. Peebler. 1996. "Department Rankings: An Alternative Approach." PS: Political Science and Politics 29: 704-17.

Montpetit, Eric, Andre Blais, and Martial Foucault. 2008. "What Does it Take for a Canadian Political Scientist to be Cited?" Social Science Quarterly 89: 802-16.

Sigelman, Lee. 2006. "Introduction to the Centennial Issue." American Political Science Review 100: v-xii.

Thatcher, Sandy, and Sanford G. Thatcher. 2007. "Response to Ranking Political Science Journals." Letter to the Editor. PS: Political Science and Politics 41: 285 . 